\title{
Development and evaluation of an educational video for families on the relief of acute pain in babies
}

\author{
Desenvolvimento e avaliação de vídeo educativo para \\ familia sobre alivio da dor aguda do bebê \\ Desarrollo y evaluación de un video educativo familiar \\ sobre el alivio del dolor agudo del bebé
}

\author{
Ariadne Pinheiro Nazario ${ }^{a}$ \\ Vanessa Ferreira de Lima ${ }^{a}$ \\ Luciana Mara Monti Fonseca ${ }^{a, b}$ \\ Adriana Moraes Leite ${ }^{a, b}$ \\ Carmen Gracinda Silvan Scochi ${ }^{\mathrm{a}, \mathrm{b}}$
}

How to cite this article:

Nazario AP, Lima VF, Fonseca LMM, Leite

AM, Scochi CGS. Development and evaluation of an educational video for families on the relief of acute pain in babies. Rev Gaúcha Enferm. 2021;42:e20190386. doi: https://doi.org/10.1590/19831447.2021.20190386
Universidade de São Paulo (USP), Escola de Enfermagem de Ribeirão Preto, Programa de PósGraduação Enfermagem em Saúde Pública. Ribeirão Preto, São Paulo, Brasil.

Universidade de São Paulo (USP), Escola de Enfermagem de Ribeirão Preto, Departamento de Enfermagem Materno-Infantil. Ribeirão Preto, São Paulo, Brasil.

\section{ABSTRACT}

Objective: To develop and evaluate an educational video for active family participation in the relief of acute pain in babies. Methods: A methodological and experimental study produced at the University of São Paulo at Ribeirão Preto School of Nursing and at a university hospital in southeastern Brazil, conducted in three operational stages, from January to July 2017.

Results: The video lasts nine minutes and 31 seconds, and it was validated by 19 expert judges with a $90 \%$ agreement among them for content and appearance items. Regarding the evaluation, 16 family members and pregnant women did it and were favorable to its use as an educational technology for learning.

Conclusions: Both the experts and the target population positively evaluated the video, which can be used as a health education strategy to empower families to engage in the baby pain relief with more autonomy and proactivity.

Keywords: Neonatal nursing. Acute pain. Health education. Family. Educational technology.

\section{RESUMO}

Objetivo: Desenvolver e avaliar um vídeo educativo para participação ativa da família no alívio da dor aguda do bebê. Métodos: Estudo metodológico, experimental, produzido na Escola de Enfermagem de Ribeirão Preto da Universidade de São Paulo e em um hospital universitário do sudeste do Brasil, conduzido em três etapas operacionais, no período de janeiro a julho de 2017.

Resultados: 0 vídeo tem duração de nove minutos e 31 segundos, foi validado por 19 juízes especialistas com concordância de $90 \%$ entre eles para os itens de conteúdo e aparência. Quanto a avaliação, 16 familiares e gestantes fizeram-na e foram favoráveis ao uso deste enquanto tecnologia educativa para aprendizagem.

Conclusões: Tanto os especialistas quanto o público-alvo avaliaram positivamente 0 vídeo, que pode ser utilizado como estratégia de educação em saúde para empoderar a família a se envolver nos cuidados de alívio da dor aguda do bebê com mais autonomia e proatividade.

Palavras-chave: Enfermagem neonatal. Dor aguda. Educação em saúde. Família. Tecnologia educacional.

\section{RESUMEN}

Objetivo: Desarrollar y evaluar un video educativo para la participación activa de la familia en el alivio del dolor agudo en el bebé. Métodos: Un estudio metodológico y experimental, producido en la Universidad de San Pablo en la Facultad de Enfermería Ribeirão Preto y en un hospital universitario del sudeste de Brasil, realizado en tres etapas operativas, de enero a julio de 2017.

Resultados: El video dura nueve minutos y 31 segundos, fue validado por 19 jueces expertos con un $90 \%$ de acuerdo entre ellos en cuanto contenido y elementos de aspecto. Con respecto a la evaluación, estuvo a cargo de 16 familiares y mujeres embarazadas, quienes se mostraron favorables a su uso como tecnología educativa para el aprendizaje.

Conclusiones: Tanto los expertos como el público evaluaron el video de manera positiva, que puede usarse como una estrategia educativa para la salud a fin de empoderar a la familia para que participe en una atención más autónoma y proactiva para el alivio del dolor del bebé

Palabras clave: Enfermería neonatal. Dolor agudo. Educación en salud. Familia. Tecnología educativa. 


\section{INTRODUCTION}

Exposure to acute pain has been documented in research studies carried out in pediatric and neonatal units of several countries. As an example, there is a Brazilian study carried out with 89 premature infants hospitalized in intensive and intermediate neonatal care units in which an exposure of babies to 6,687 painful procedures during their first 14 days of life was verified, with a mean of 75.13 procedures per premature infant and a daily mean of 5.37 painful interventions per baby ${ }^{(1)}$.

Babies, whether premature or not, are exposed to painful procedures during hospitalizations and childhood to comply with the vaccination schedule, for example. Therefore, preventing and relieving pain in neonates and lactating women is a frequent challenge in the health care field, as adequate treatment of pain is considered an essential human right. In Brazil, children have the right to not feeling pain, as it is warranted by the Resolution 41/95 - Rights of Hospitalized Children and Adolescents ${ }^{(2)}$.

A few years ago, several pharmacological and non-pharmacological interventions have been developed and studied for the relief of neonatal pain ${ }^{(3)}$, including: breastfeeding, use of breast milk ${ }^{(4)}$, non-nutritive sucking ${ }^{(3-4)}$, skin-to-skin contact, and touching, holding, and rocking newborns (NBs). Furthermore, there are supporting actions that can facilitate the treatment of pain, such as facilitated tucking, swaddling, and reduction in environmental stimuli(4).

Given the importance of the treatment of pain in NBs and the proven effectiveness of non-pharmacological methods for pain relief, especially in interventions with an active participation of the parents, an educational video was developed to encourage families to participate in the treatment of acute pain in their children.

Interactive forms of health education, such as the educational video, have been signaled as fruitful in the teaching-learning process ${ }^{(5)}$. The educational video consists in a teaching and technological instrument that provides knowledge, helps in the development of critical consciousness( ${ }^{(6)}$, and can be used to promote health (7), prevent complications, develop skills, and favor autonomy and confidence of patients $5^{(8)}$ and family members, as well as an important vehicle for the apprehension of new knowledge.

In view of the evidence of efficacy of the educational video as an instrument in health education, assuming that for the theme of this study this tool can innovatively contemplate learning of the content directed to the target population beyond the possibility of an extensive promotion to other services electronically, this strategy was chosen to configure the educational technology produced in this research.
Considering that the presence of families needs to be motivated and not ignored within neonatal units, the following questions were raised: How to prepare families to participate in the relief of acute pain in their babies? How do families perceive this possibility of participation in the care of children during painful procedures? Can an educational video help families in this process? And thus, valuing the care provided by families, especially by parents to their children, based on the quality of the guidelines and on the partnership with the team, an educational material to enable health education was developed.

\section{OBJECTIVE}

To develop and evaluate an educational video for the active participation of families in the relief of acute pain in babies.

\section{METHODS}

This paper arises from the master's degree dissertation entitled: "Development and evaluation of an educational video for family awareness and education on the relief of acute pain in infants". This is a methodological study of experimental development conducted in three operational stages: preparation of the video based on scientific evidence and clinical experience of the main researcher, appearance and content validation of the video by experts, and evaluation of the video by the target population. It was developed from January to July 2017 at the Ribeirão Preto School of Nursing at the University of São Paulo (Escola de Enfermagem de Ribeirão Preto da Universidade de São Paulo, EERP/USP) and at a university hospital in the Southeast of Brazil.

The convenience sampling was composed of 19 professionals participating in the validation of the video, 13 being trained in Nursing and 6 in the area of communication and/ or audiovisual technologies, considered specialists or experts, and intentionally selected according to their expertise related to the theme of the study. The inclusion criterion for experts in the Nursing area was having at least three years of professional experience, a master's degree, or being a specialist in one or more areas of interest. As for the experts in audiovisual technologies, professionals acting in the areas of audiovisual and/or communication technologies at the EERP/USP and at the hospital where the study was carried out were sought, having as inclusion criterion at least one year of experience in the area of interest.

The video was evaluated by 16 family members, being eight mothers and one father of term or premature NBs assisted in the Neonatal Intensive Care Unit (NICU) and/ 
or Neonatal Intermediate Care Unit (NIMCU), five pregnant women assisted in the outpatient clinic of the hospital, and their two of their companions, who were present in the appointment. As inclusion criterion for parents in the neonatal units, it was defined that they should have NBs hospitalized for at least three days in the NICU and/or NIMCU; for pregnant women, being pregnant with prenatal care in obstetric outpatient clinic, except for malformation outpatient clinic; and, for the pregnant women's companion, the only criterion was accompanying them in the outpatient clinic.

In the pre-production of the educational video, a script was prepared based on the literature review conducted about the theme approached in the video and on the clinical experience of the main researcher, containing detailed information that helped in the initial perspective about what would be presented in it.

The script preparation had several versions, provided that, initially, as it was prepared based on scientific studies, it was presented with a specific language and, then, it was gradually translated to a more adequate and accessible vocabulary for the target population, aiming at an educational technology that may be widely used, with the possibility of reaching people with any level of instruction.

The completed script was forwarded to the technical team of multimedia creation, which, together with the main researcher, prepared the storyboard, whose purpose is to guide the creative process at other stages of production. The storyboard was analyzed by the researchers regarding its adequacy and their considerations were implemented.

Video production consisted of filming scenes that were part of the script, which was performed by the main research$\mathrm{er}$, in the premises of the hospital's NIMCU upon agreement in participating and signature of the Authorization Term for Use of Image and Sound by the babies' mothers. The painful procedures occurred according to the routine of the hospitalization unit, where the main researcher remained and, when it was identified that a procedure to be carried out could involve the video's script, she approached the mother and the health care professional to ask for consent to film them. She herself suggested the interventions, which were already familiar to the health professionals who conducted the procedure. For filming the scenes, four babies, two mothers, and two health professionals participated. It is important to note that the researcher did not interfere in the procedures, as the camera was positioned in a way that it did not cause any troubles to the professionals, and no procedures were carried out, either repeated or interrupted, due to the recording.

Also at the video production stage, characters and scenarios were created, animations were developed, as well as narration, and selection of texts and images. There was the participation of a technical team specialized in the creation of multimedia so that a good quality production was obtained, and the accuracy of the images for post-production was evaluated.

Post-production included the edition of the scenes recorded, narration, inclusion of the characters created in images and animations, texts, and audio. It was conducted with directions of the researcher together with two audiovisual technicians with experience in producing educational videos, members of the outsourced technical team specialized in the creation of multimedia.

After concluding post-production, the video was subjected to the validation by experts in Nursing and audiovisual technologies, as well as to the evaluation by the target population, as detailed below. Suggestions and considerations were analyzed and accepted when they were considered relevant. Subsequently, the final changes were forwarded to the creation and edition technical team, which concluded the development of the educational technology.

The video was transferred to DVD (Digital Versatile Disk), distributed to the hospital sectors, and made electronically available to the experts in Nursing for use in their services.

The experts in both areas received an electronic message with an invitation to participate in the research, instructions on how to conduct the validation, a temporary link to access the video and another one to access the electronic forms that needed to be filled, according to the area of expertise. All filled the characterization instrument related to their occupation and evaluated general impressions of the video, and only the experts in Nursing analyzed its content.

Regarding acceptance to participate in the study, among the experts in Nursing, none of them refused to take part and, of the nine audiovisual experts invited, six sent a reply with an evaluation of the video.

For the validation of the video by the experts, an instrument ${ }^{(9)}$ regarding the evaluation of general impressions and content was adopted.

In the general impressions instrument, five positive statements related to the following aspects are included: the video favors learning, animations and images contribute to learning, it has indication of use as an educational tool, and it would be recommended to instruct fathers and pregnant women. There are also two questions about the need to change or include anything in the video, requiring an explanation if the answer is positive.

Regarding content evaluation, 18 positive statements constituted the instrument, being associated with the clear definition of the video's objectives, consistency with objectives proposed; content updated and consistent with the 
target population, clear and concise information, sufficient for the users, logically organized, easy-to-read texts, presentation that catches the attention, relevance of figures, images, and sounds, correct use of grammar, video that simulates reality, motivates learning, facilitates content retention in the memory, and enables learning based on previous experience.

In both instruments there are statements about the aspects mentioned that are relevant to the area of expert evaluation, as well as the summative method, known as a Likert scale containing the following options: strongly disagree, disagree, agree, strongly agree, and neutral. Therefore, for each sub-item of the instruments, the participant evaluated the statements presented and chose an option among the established ones and, if necessary, provided comments/ suggestions in a space for this purpose.

The target population that evaluated the video was selected for presenting a profile similar to the clients to which it is directed; regarding the experience of having a baby (hospitalized or not), being pregnant women, and family members.

For evaluating the educational video from the perspective of fathers and pregnant women, first, the media was shown to the participant individually on a tablet, and then an interview was conducted based on a structured questionnaire composed of two parts: the first has questions to define the interviewee and the baby, the experience of the fathers during painful procedures and of interviewees in the outpatient clinic for pregnant woman; and the second, questions about the perception and evaluation of the educational video, considering that, after all the questions, there was a space reserved for open answers if the participant wanted to make comments about the answers given.

During data analysis, the educational video was considered to be validated if $80 \%$ of the experts chose the agree or strongly agree options in each appearance and content item appreciated, according to a criterion adopted in another study ${ }^{(9)}$.

For the data analysis regarding the process of validation of the video and also for its evaluation, descriptive statistics was used.

The statements recorded by experts in an on-line form through comments/suggestions of the criteria evaluated in general impressions and content analysis of the video were cursively registered in the results.

The answers to the open questions and suggestions of the clients were presented upon full record made by the main research as verbalized by the interviewees, with not many conventions of the standard formal language, considering that each interviewee was identified by codes with one letter followed by a sequential number (E01, E02... E16) to preserve anonymity, and the statements were presented grouped according to aspects relevant to the evaluation of the educational video.

The study was approved by the Research Ethics Committee of the EERP/USP, under opinion No.1,697,431 and Certificate of Presentation for Ethical Appraisal (Certificado de Apresentação para Apreciação Ética, CAAE) No. 58757216.1.0000.5393. Consent from the Department of Gynecology and Obstetrics and the Department of Pediatrics was also obtained under the issuance of a consolidated opinion of the hospital's Research Ethics Committee.

\section{RESULTS}

As an educational technology, the educational video was entitled "Com amor, sem dor" ("With love, without pain") (Figure 1), lasting nine minutes and 31 seconds. It is available for virtual learning environments in DVD format and in a Full HD (1920x1080) MP4 file for sharing.

The scenes recorded were sufficient to the edit the video according to the script established, with no need for adjustments, and the images obtained were capable of clearly showing the painful procedures and the interventions conducted, as described in Chart 1.

Of the 13 experts in Nursing, all were nurses, aged between 27 to 52 years old, nine (69.2\%) from the state of São Paulo and four (30.8\%) from Paraná. Their training time ranged from 5 to 32 years, with a mean of 18.3 years, and their professional experience in the area ranged from 4 to 30 years, with a mean of 13.3 years. Regarding their maximum academic degrees, three (23.0\%) had a master's degree, three (23.0\%) were PhDs, three (23.0\%) were specialists, two (15.5\%) had post-doctorate degree, and two (15.5\%) had a master's degree and were specialists.

In the evaluation by the experts in Nursing, regarding the general impressions, the answers for all the criteria were agree or strongly agree and, for all items, the strongly agree option obtained values higher than $80 \%$. For the indication of items to be modified, six (46.2\%) nurses appointed suggestions, namely: changing the phrase in the video that indicated that the baby feels pain, emphasizing the fact that the baby feels pain, and reducing the length of the video. Six (46.2\%) nurses made suggestions for including items, namely: differentiating strategies of "swaddling" and "facilitated tucking", explaining the term "heel puncture", identifying in writing the graphic element of the video that represents pain, and including more real scenes and background music throughout the video.

In addition, regarding the general impressions, suggestions/observations were made, namely: narration is too fast at the beginning of the media and questions about the 

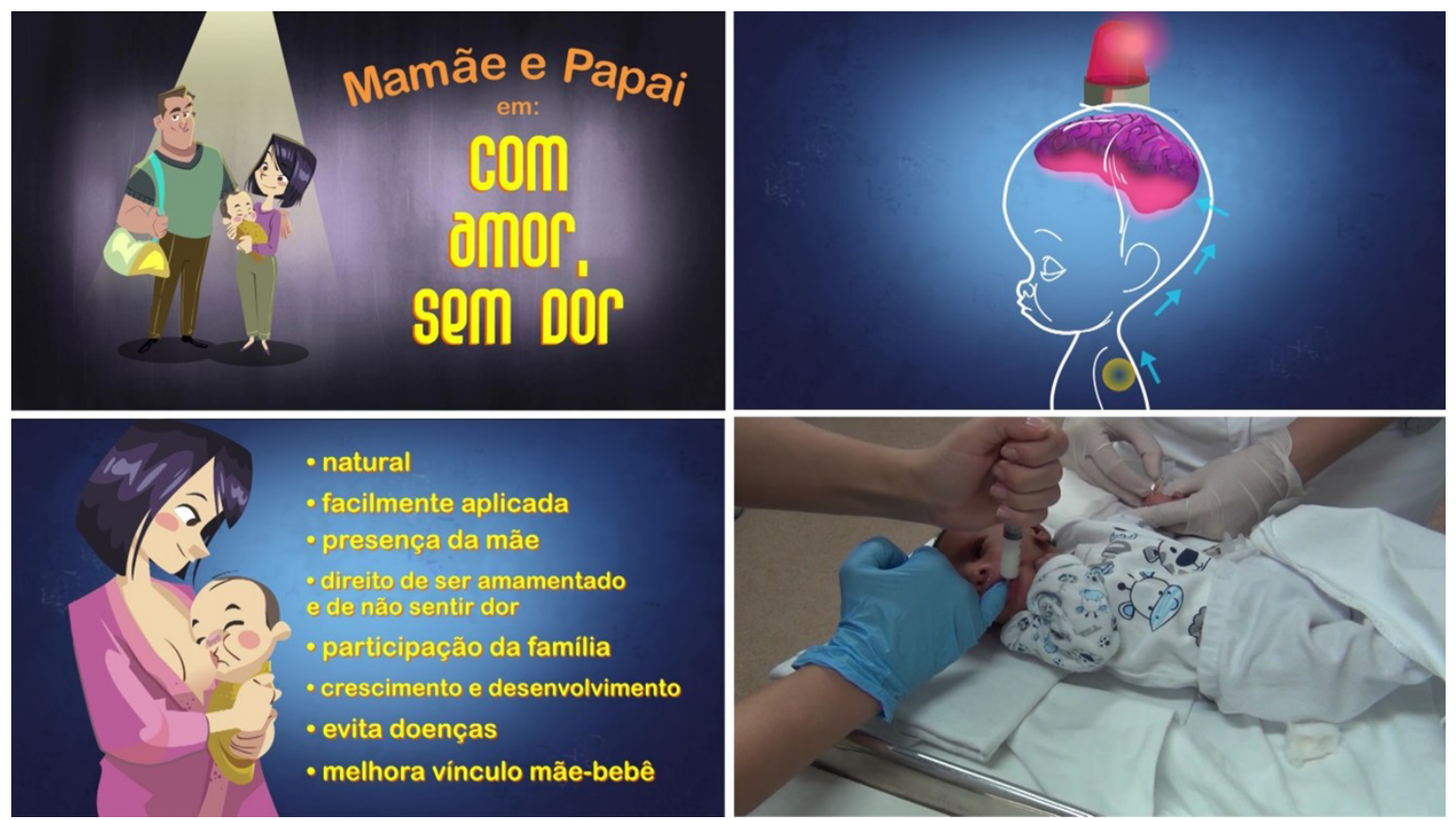

Figure 1 - Pictures of parts of the video

Source: The authors (2017)

\begin{tabular}{|l|l|}
\hline Procedure/Scene & Intervention \\
\hline Baby Crying & $\begin{array}{l}\text { No intervention - the spontaneous crying of a baby } \\
\text { was recorded }\end{array}$ \\
\hline $\begin{array}{l}\text { Blood collection by venipuncture from the back of } \\
\text { the hand }\end{array}$ & Breastfeeding \\
\hline $\begin{array}{l}\text { Blood collection by venipuncture from the back of } \\
\text { the hand }\end{array}$ & Skin-to-skin contact with the mother \\
\hline Blood collection by arterial puncture (radial artery) & $\begin{array}{l}\text { Use of expressed breast milk and non-nutritive sucking } \\
\text { with a protected finger }\end{array}$ \\
\hline
\end{tabular}

Chart 1 - Scenes, procedures and interventions recorded for the video Source: The authors (2017).

efficacy in instructing pregnant women. Regarding content evaluation: explaining more technical terms, reducing the content, dividing the video, including information on how to position babies for skin-to-skin contact and breastfeeding, adding more texts, illustrating other painful procedures in addition to the ones exposed, and including real images of the other interventions mentioned.

The video was praised by the experts, who gave favorable opinions about its use not only for the study target population, but also for continuing training of health professionals, highlighting the importance of providing strategies for a better approach to the fathers. The use of real images was quite valued.

With respect to content evaluation, except for the "information is clear and concise" and "educational video enables learning based on previous experience of the user" criteria, all the answers were agree and strongly agree, considering that, for the latter, the answers were above 69\% in all the criteria. In the "information is clear and concise" criterion, one (7.7\%) nurse stated not knowing to answer, arguing that the language seems clear; however, as there is a lot of information, possibly new for the clients, and offered all together 
in a short time, the professional suggested considering an attempt to simplify even more the language and reduce the content, as well as provide "fragmented"versions of the video as smaller medias presenting each strategy individually. In its turn, in the "the educational video enables learning based on previous experience of the user" criterion, it was registered in the observations that, regardless of clients having or not previous experience, the video is capable of encouraging and favoring learning.

The groups of experts in audiovisual technologies was composed of three (50.0\%) female professionals, and three (50.0\%) male professionals, aged between 23 to 54 years old and with a mean of 41.2 years old; all (100\%) from the state of São Paulo. The time of professional experience in the area ranged from 1 to 26 years, with a mean of 15.5 years. Regarding maximum academic degrees, four (66.7\%) had some specialization, and two (33.3\%) only an undergraduate degree, and the areas were the following: visual communication, systems analysis, graphic design, journalism, and administration. With respect to the performance in the development and/or edition of videos, five (83.3\%) declared working in this area, and their working time ranged from 2 to 15 years, with a mean of 9 years.

In all the criteria, these experts answered agree or strongly agree. Regarding the desire of changing something in the video, three (50.0\%) made suggestions, namely: removing the image that represents pain and changing details of the characters'design. For the inclusion of any item, two (33.3\%) suggested including subtitles for hearing impaired people and adding more animations. The only suggestion/observation made was that the video should be shorter.

The results showed an agreement over $90 \%$ if adding up the agree and strongly agree answers for each appearance and content item; thus, the video we validated by the experts.

For the evaluation of the video by the target population, the age of the interviewees ranged from 18 to 37 years old, with a mean of 27.2 years old. Of the participants, nine (56.3\%) declared not currently having an occupation and seven (43.7\%) had one. Training ranged from incomplete elementary school to graduation, given that ten (62.5\%) interviewees have complete high school, three (18.6\%) have incomplete elementary school, one (6.3\%) has incomplete high school, one (6.3\%) has a college degree, and one (6.3\%) is a post-graduate. Of the interviewees, three (18.18\%) were male and 13 (81.2\%) were female. The number of children ranged from one to four, with a mean of 3.5 .

For the parents interviewed in the NICU or NIMCU, the babies' chronological ages coincided with the length of hospital stay, as all remained hospitalized since their birth, ranging from three to 46 days, with a mean of 18.8 days of life and hospitalization. Five (55.5\%) babies were female and four (44.5\%) were male. Gestational age at birth ranged from 26 weeks to 39 weeks, with a mean of 29 weeks, and birth weight varied from 595 grams to 3,950 grams, with a mean of 2,026 grams. No one declared to have carried out skinto-skin contact or breastfeeding during a painful procedure.

Of the fathers interviewed in the neonatal units, five $(55.6 \%)$ revealed to have already witnessed a painful procedure of their baby, namely: blood collection, heel puncture, chest drain insertion, and fundus examination. When questioned about how they felt by witnessing a painful procedure performed on their children, the answers evidenced that, in spite of not feeling well, feeling sorry for their babies, and feeling distress, they understood that it was for their good, as shown below:

I felt bad seeing that procedure [referring to blepharostat, instrument used to for keeping eyelids apart during the examination] in her eye. I felt anguish seeing her [NB] suffering. (E16)

\section{I felt bad, but I know it's for her own sake. (E01)}

Of the interviewees in the outpatient clinic, one (14.3\%) was in the second trimester of pregnancy and six (85.7\%) in the third. The reasons of the monitoring in the outpatient clinic were as follows: maternal disease (71.4\%), multiple pregnancy (114.3\%), and intrauterine growth restriction of fetus (14.3\%). All reported that they imagine that their babies will go through some painful procedure after birth, such as: vaccine (five times) and heel prick test (four times).

Regarding the evaluation of the video, eight (50.0\%) representatives of the target population considered it excellent, and eight (50.0\%) considered it very good. The 16 interviewees (100\%) would indicate/recommend it to other fathers/ pregnant women and, when questioned about their reasons, they asserted that the video brings new and important information, being self-explanatory, as it is possible to notice in the statements:

\section{There's a lot of information that people don't know. I only knew pain relief with breastfeeding. (E01) \\ Really explanatory, they're simple methods that help the baby not feel pain. (E11 - Father) \\ It teaches well about how to deal with pain in babies, especially for first-time mothers. (E15)}

When they were questioned if the video could help them in caring for pain in their babies, all (100\%) answered that it could, mentioning the interventions explained in the video and relating them to potential painful procedures, which is verified in the following excerpts: 
Breastfeeding when collecting blood. (E04)

When venous access is needed, to prevent that he feels a lot of pain. (E05)

Making the skin-to-skin contact, identify the pain, and knowing how to deal with it, and the presence of the family, I'm going to participate more, help more. (E14-Father)

In the open question about the care actions taught in the video, the answers evidence that the interviewees consider the important care actions easy to be applied and recognize the importance of the image of families, as in the following statements:

It fosters breastfeeding and allows the family to also minimize pain. (E02)

They are very important, the moments of affection of the father and the mother, the baby feels a lot the presence of the family. (E06)

All (100\%) reported the wish to carry out the care actions taught in the video, explaining that, with, this they may help in the relief of pain in the baby and reduce suffering, and even considering it a love gesture, as shown below:

For love, not to see my baby suffering. (E10)

For the good of the baby, if there's a way of taking the baby's pain away, the mom does everything it takes. (E12)

I'll absolutely do it, because then I don't see his suffering while he takes an injection. (E13)

Regarding when the care actions approached could be applied, the moment of vaccination was the most mentioned (13 times), followed by blood collection (seven times), heel prick test (five times), and other single mentions, such as puncture for venous access, certain procedures of physical examination in medical appointment, blood collection in case of colic, injection, and tooth eruption.

When they were asked to attribute a grade from zero to ten to the video, the lowest grade was nine, and the highest was ten, with a mean grade of 9.9 for the video by the target population. None of the interviewees made suggestions to improve or change the video.

\section{DISCUSSION}

Creating and providing knowledge generates great responsibility in those who propose to do so. This dissemination should be made in order to favor the understanding of information so the process of assimilation of content and the creation of knowledge are effectively achieved ${ }^{(8)}$ and enable acquisition of content, empowerment and autonomy of the involved ones, with an objective, clear and easy approach to be applied, directed to reality, which echoes in the way in which people are going to face the care demands ${ }^{(6)}$.

Regarding the creation of educational materials, it is essential to conduct their validation with experts because, as they show mastery of the content, they are capable of helping in the prevention of inaccurate results or biased measures that can lead to wrong conclusions, resulting in better prepared and more useful instruments for the target population ${ }^{(10)}$.

In general, it is perceived that, in this study, the evaluation of the video by experts was very positive, emphasizing in the comments the lack of technological educational materials for health education. This analysis corroborates with the findings of the Brazilian study that aimed at creating an educational video for guiding and teaching parents, family members, and professor about the main behaviors expressed by schoolaged individuals with difficulties in seeing it, in which experts considered the video content relevant/updated ${ }^{(7)}$.

The evaluation of the video by the target population was essential to confirm the validation made by the experts. It is noticed that the participants questioned if this type of video would always be shown because they considered such activity as important. They were motivated in continuing with the discussion about the subject matter after watching the media and answering the research questionnaires, evidencing that the tool aroused interest in the theme.

The enthusiasm shown by the family members when watching the video is similar to what was presented in the study that sought to know the perceptions of participants of a support group for people with colostomy about the use of an educational video as a resource for health education activities, in which it was verified that, by seeing the care, people get close to the context and are encouraged to talk about the theme and then they acquire knowledge ${ }^{(6)}$.

Recent research studies have proven the efficacy of using educational technology strategies for the processes of teaching and learning not only within the context of health education for patients and family members ${ }^{(5-6,11-13)}$, but also as a support for the professionals. Educational videos have been used in several pedagogical experiences showing the relevance of their applicability in the teaching-learning process, as they combine several elements, such as images, text, and sound in a single object of knowledge promotion ${ }^{(6)}$.

Technologies in health, especially in Nursing, show evident progress regarding care, aiming at a direct improvement in the provision of assistance to patients and their family members ${ }^{(6,11)}$, as it motivates, arouses curiosity, and stimulates the caregiver's participation in the care actions ${ }^{(5)}$. 
Regarding the content approached in this video, it is understood that it is a theme little explored when it comes to providing information about the pain of babies to the parents, probably because it can cause sadness in those who do not want to see their children suffering, creating resistance in the professionals to address the subject matter.

A study carried out with parents of babies hospitalized in a NICU aiming to assess their knowledge about breastfeeding, skin-to-skin care and sweetened solutions as neonatal analgesic strategies, as well as to assess the parents' perception about the viability, acceptance, and usefulness of a version in Portuguese of a video, verified that the majority of the interviewees did not know the analgesic effects of the three interventions. Regarding the video, all the interviewees considered it a useful resource, easy to understand and to apply in real life, and would recommend it to other parents. In addition, $92 \%$ of them classified the duration of the video as ideal and none of them showed any discomfort by watching it or signaled any negative aspect related to the media. Therefore, it is possible to say that the video is an important tool in health education ${ }^{(12)}$, as well as in this study, in which families acknowledged the possibility to acquire quality information from it.

Among the professionals, research studies on the management of pediatric pain have gained ground, considering that educational videos can be useful, as they offer the professionals, family members, and children evidence-based content to reduce pain ${ }^{(14)}$.

Pain management in babies has spread more and more with great assistance impacts but, when it comes to expanding it to the family members, or the use of strategies that enable the participation of families in the care of babies'pain, this scenario is poorly consolidated. In a systematic review of videos on YouTube available in Portuguese that showed collection of neonatal blood samples to assess pain management and the comforting measures used, it was verified that, of 68 videos included in the study, heel puncture was performed in 62 and 49 babies were held by an adult during the procedure; however, the breastfeeding and swaddling measures were rarely implemented, $3 \%$ and $1.5 \%$ respectively, showing that the treatment of pain and suffering in NBs during the procedures is still insufficiently practiced ${ }^{(15)}$.

Even with the involvement of incipient families, the dissemination of content related to the mitigation of neonatal pain is being expanded. In a research study that assessed the reach and acceptability of a video posted on YouTube directed to parents, which showed three strategies (breastfeeding, skin-to-skin contact, and sucrose) to reduce pain in NBs during blood collection, it was verified that this video had over 10,000 views after a year on the web, showing that it can be a far-reaching resource to spread information. Moreover, the results suggest that the use of media can be recommended and that the strategies taught for pain management can be practiced by the parents ${ }^{(13)}$.

Although it was not the objective of this study, the results signal that families are little used in this type of care related to the management of acute pain resulting from knowingly painful procedures despite the evidence on the effectiveness of interventions that involve them, especially breastfeeding, use of breast milk ${ }^{(16)}$, and skin-to-skin contact ${ }^{(4)}$. This observation was made in this study because no mothers declared to have carried out skin-to-skin contact or breastfeeding during a painful procedure, despite the fact that all the interviewees showed interest and desire in adopting the interventions presented in the educational video, considering this participation as a love gesture.

It is known that families are not still truly involved in the care process of the neonatal units. A Brazilian study carried out with ten mothers in order to identify driving and hindering forces involved in the process of motherhood to NBs hospitalized in a NICU, it was verified that part of the multi-professional team encourages their participation in the care of the baby; on the other hand, other professionals hinder the interaction among them, act with authoritarianism, criticizing actions performed by mothers, and do not give space so that they can learn how to take care of their children ${ }^{(17)}$. Considering this organizational context of assistance, it is believed that free access to the video developed in this study may contribute to the empowerment of parents and families to actively seek ways to adopt these interventions, provided with necessary knowledge and sensitization, without totally depending on the professional team's determinations about what the best moment and procedures to be carried out in these care actions are.

A study carried out in Finland that described parents' perceptions about factors that influence their participation in the relief of pain in NICUs revealed that aspects like good communication, counseling offered by teams, awareness of parents about their own roles, motivation to participate in actions for pain relief, and adequate facilities in units for families are essential to promote their participation in the relief of neonatal pain. In contrast, a restrictive environment, lack of knowledge, daily tasks, and medical procedures worsen the clinical status of babies or mothers, emotions awakened by witnessing procedures and pain, the fact of being underestimated by the teams, and the uncertainty of parenthood hinder family involvement. Accordingly, it is understood that, to promote a better inclusion of parents in the relief of NBs' pain, it is indispensable to offer information consistent with the needs presented by them ${ }^{(18)}$. Thus, it is 
believed that the educational video and other strategies can be used as tools to provide information to parents and to relieve their negative feelings in the experience of pain in their babies.

In the video validation, an expert got concerned about showing the video to pregnant women, considering that the pregnancy and the prenatal period provides a lot of information to women. Although, the media evaluation by them and their companions awaiting the medical appointment was quite positive. It is important to turn the patients' waiting time into a health education moment, with audiovisual strategies, e.g., considering this waiting space as potentially capable of becoming a productive environment ${ }^{(19)}$.

It is considered that, in the prenatal period, parents are preparing themselves to receive a baby and are interested in acquiring information that will make care easier; thus, the waiting room of prenatal medical appointments becomes a favorable place to offer these data, as the information taught in the video is applicable to all babies, either healthy or at risk of diseases and harms.

A study carried out with pregnant women and women with children under three years old verified that they used to watch videos on digital platforms like YouTube, e.g., in order to prepare themselves for birth and learn about care actions, such as changing diapers and children's diet. They consider videos important media because the content can be seen several times, helping in the acquisition of knowledge. In addition, the majority is produced by health professionals or by other parents who already experienced the situation exposed; for this reason, this is valued by the women ${ }^{(20)}$. Thus, the educational video presented in this paper can be considered an interesting vehicle of information for pregnant women during the prenatal period.

In this context, it is possible to say that the educational video, as a supportive health education activity for the insertion of families in pain management, can contribute to non-traumatic, humanized, and developmental care, as well as to strengthen the family unit ${ }^{(6)}$ and to integrate the concept of humanized welcoming, pursuant to the proposals of the Unified Health System (Sistema Único de Saúde, SUS).

\section{口 CONCLUSIONS}

In general, the diverse evidence on the effectiveness of interventions for pain management are underused and acute pain is undertreated, even more when it is about those that involve families. There is a series of factors that influence this context, resistance of health teams and lack of information provided to parents being some of the main problems. It is believed that health teams are concerned in preventing and relieving pain in babies, but they tend to choose more practical measures that do not require the presence of the parents. In contrast, interventions involving family, apart from being more natural, bring benefits beyond the relief of acute pain in that occasional situation, but also in the development of the babies and in the construction of affective bonds with the family.

Within the current context, the presence of computers and interactive technologies in the daily life of society is undeniable, which has a huge power of drawing the attention, since they combine several elements that awaken various senses: images, animations, music, colors, lighting, interactivity, and texts, among others, in a single object to promote knowledge.

The video "With love, with no pain" was validated by nurses and audiovisual professionals and positively evaluated by the target population of pregnant women and fathers, being an educational technology that can have a favorable impact with its use as a health education strategy to empower families to engage in baby pain relief with more autonomy and proactivity. The use and the potential contributions of this technological product for professional training are also glimpsed, and it may be another tool for the training and continuing education of health teams.

As health educators, nurses should use creativity to prepare materials that facilitate teaching and learning, as it is through health education that distress will be reduced and planning and implementation of cares by families will be appropriated, aiming at the improvement of the quality of life of babies and their family members in the short- and long-term.

Thus, it is necessary to increasingly encourage the development and use of new care strategies with educational technologies in the Nursing practice, aiming at non-traumatic, humanized, and developmental care with the enhancement of child and family health care in Brazil.

Study limitations: it is clear that, for being an educational video, it should be periodically reviewed in order to update it and so that it may be continuously used by families in various scenarios of neonatal care and child health, focused on the use of any and all strategies scientifically proven for the relief of acute pain in babies that involve families.

Further research studies are suggested which assess the impact of using this educational video at a large scale in the health services under the perspective of professionals and families. 


\section{REFERENCES}

1. Bonutti DP, Daré MF, Castral TC, Leite AM, Vici-Maia JA, Scochi CG. Dimensioning of painful procedures and interventions for acute pain relief in premature infants. Rev Latino-Am Enfermagem. 2017;25:e2917. doi: https://doi. org/10.1590/1518-8345.1387.2917

2. Conselho Nacional de Defesa dos Direitos da Criança eAdolescente (BR). Resolução No.41, 13 de outubro de 1995. Dispõe sobre os direitos da criança hospitalizada. Diário Oficial. 1995 out 17 [cited 2019 May 30];138(199 Seção 1):16319-20. Available from: https://pesquisa.in.gov.br/imprensa/jsp/visualiza/index. jsp?data $=17 / 10 / 1995 \&$ jornal $=1 \&$ pagina $=7 \&$ totalArquivos $=80$

3. Costa T, Rossato LM, Bueno M, Secco IL, Sposito NPB, Harrison D, et al. Nurses' knowledge and practices regarding pain management in newborns. Rev EsC Enferm USP. 2017;51:e03210. doi: https://doi.org/10.1590/ s1980-220x2016034403210

4. Maciel HIA, Costa MF, Costa ACL, Marcatto JO, Manzo BF, Bueno M. Pharmacological and nonpharmacological measures of pain management and treatment among neonates. Rev Bras Ter Intensiva. 2019;31(1):21-6. doi: https://doi.org/10.5935/0103-507x.20190007

5. Razera APR, Trettene AS, Mondini CCSD, Cintra FMRN, Tabaquim MLM. Education video: a training strategy for caregivers of children with cleft lip and palate. Acta Paul Enferm. 2016;29(4):430-8. doi: https://doi. org/10.1590/1982-0194201600059

6. Dalmolin A, Girardon-Perlini NMO, Coppetti LC, Rossato GC, Gomes IS, Silva MEN. Education video as a healthcare education resource for people with colostomy and their families. Rev Gaúcha Enferm. 2016;37(esp):e68373. doi: https://doi.org/10.1590/1983-1447.2016.esp.68373

7. Rodrigues Junior $\mathrm{IC}$, Rebouças CBA, Castro RCMB, Oliveira PMP, Almeida PC, Pagliuca LMF. Development of an educational video for the promotion of eye health in school children. Texto Contexto Enferm. 2017;26(2):e06760015. doi: https://doi.org/10.1590/0104-07072017006760015

8. Moreira CB, Bernardo EBR, Catunda HLO, Aquino PS, Santos MCL, Fernandes AFC. Construçã̃o de um vídeo educativo sobre detecção precoce do câncer de mama. Rev Bras Cancerol. 2013 [cited 2017 Oct 19];59(3):401-7. Available from: https://rbc.inca.gov.br/revista/index.php/revista/article/view/505/302

9. Góes FSN, Fonseca LMM, Carvalho MCC, Leite AM, Scochi CGS. Evaluation of the virtual learning object "Diagnostic reasoning in nursing applied to preterm newborns". Rev Latino-Am Enfermagem. 2011;19(4):894-901. doi: https://doi. org/10.1590/S0104-11692011000400007
10. Leite SS, Áfio ACE, Carvalho LV, Silva JM, Almeida PC, Pagliuca LMF. Construction and validation of an Educational Content Validation Instrument in Health. Rev Bras Enferm. 2018;71(Suppl 4):1635-41. doi: https://doi. org/10.1590/0034-7167-2017-0648

11. O'Sullivan TA, Cooke J, McCafferty C, Giglia R. Online Video Instruction on Hand Expression of Colostrum in Pregnancy is an Effective Educational Tool. Nutrients. 2019;11(4):883. doi: https://doi.org/10.3390/nu11040883

12. Bueno M, Costa RN, Camargo PP, Costa T, Harrison D. Evaluation of a parenttargeted video in Portuguese to improve pain management practices in neonates. J Clin Nurs. 2018;27(5-6):1153-9. doi: https://doi.org/10.1111/ jocn. 14147

13. Harrison D, Reszel J, Dagg B, Aubertin C, Bueno M, Dunn S, et al. Pain management during newborn screening: using YouTube to disseminate effective pain management strategies. J Perinat Neonat Nurs. 2017;31(2):1727. doi: https://doi.org/10.1097/JPN.0000000000000255

14. Farkas C, Solodiuk L, Taddio A, Franck L, Berberich FR, LoChiatto J, et al. Publicly available online educational videos regarding pediatric needle pain: a scoping review. Clin J Pain. 2015;31(6):591-8. doi: https://doi.org/10.1097/ AJP.0000000000000197

15. Bueno M, Nishi ET, Costa T, Freire LM, Harrison D. Blood sampling in newborns: a systematic review of YouTube videos. J Perinat Neonatal Nurs. 2017;31(2):1605. doi: https://doi.org/10.1097/JPN.0000000000000254

16. Harrison D, Reszel J, Bueno M, Sampson M, Shah VS, Taddio A, etal. Breastfeeding for procedural pain in infants beyond the neonatal period. Cochrane Database Syst Rev. 2016;10(10):CD011248. doi: https://doi.org/10.1002/14651858. CD011248.pub2

17. Santos LF, Souza IA, Mutti CF, Santos NSS, Oliveira LMAC. Forces interfering in the mothering process in a Neonatal Intensive Therapy Unit. Texto Contexto Enferm. 2017;26(3):e1260016. doi: https://doi. org/10.1590/0104-07072017001260016

18. Palomaa AK, Korhonen A, Pölkki T. Factors influencing parental participation in neonatal pain alleviation. J Pediatr Nurs. 2016;31(5):519-27. doi: https://doi. org/10.1016/j.pedn.2016.05.004

19. Rodrigues LP, Nicodemos FT, Escoura C, Lopes FG, Ferreira MA, Santos AS. Waiting room: space for health education. REFACS. 2018;6(3):500-7. doi: https://doi.org/10.18554/refacs.v6i3.2917

20. Lupton D. The use and value of digital media for information about pregnancy and early motherhood: a focus group study. BMC Pregnancy Childbirth. 2016;16:171. doi: https://doi.org/10.1186/s12884-016-0971-3 
- Acknowledgments:

To the National Council for Scientific and Technological Development (CNPq) for their funding to develop the educational video.

\section{- Authorship contribution:}

Conceptualization: Ariadne Pinheiro Nazario; Carmen Gracinda Silvan Scochi.

Data curation: Ariadne Pinheiro Nazario; Carmen Gracinda Silvan Scochi.

Formal analysis: Ariadne Pinheiro Nazario; Carmen Gracinda Silvan Scochi.

Funding acquisition: Carmen Gracinda Silvan Scochi.

Investigation: Ariadne Pinheiro Nazario; Carmen Gracinda Silvan Scochi.

Methodology: Ariadne Pinheiro Nazario; Carmen Gracinda Silvan Scochi.

Project management: Ariadne Pinheiro Nazario; Carmen Gracinda Silvan Scochi.

Resources: Carmen Gracinda Silvan Scochi.

Software: Ariadne Pinheiro Nazario; Carmen Gracinda Silvan Scochi.

Supervision: Carmen Gracinda Silvan Scochi.

Validation: Vanessa Ferreira de Lima; Luciana Mara Monti Fonseca; Adriana Morais Leite; Carmen Gracinda Silvan Scochi.

Visualization: Ariadne Pinheiro Nazario; Vanessa Ferreira de Lima; Luciana Mara Monti Fonseca; Adriana Morais Leite; Carmen Gracinda Silvan Scochi.

Writing- Original draft: Ariadne Pinheiro Nazario; Carmen Gracinda Silvan Scochi.

Writing - Review and editing: Vanessa Ferreira de Lima; Luciana Mara Monti Fonseca; Adriana Morais Leite; Carmen Gracinda Silvan Scochi.

- Corresponding author:

Ariadne Pinheiro Nazario

Email: ariadnenazario@hotmail.com 